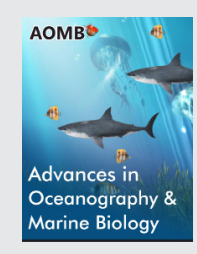

\title{
Presentation of Pukchang fish farm (Democratic People Republic of Korea) in the context of a joint partnership project funded by EU
}

\author{
Philippe Lebailly ${ }^{1 *}$, Yong Jin Kang ${ }^{2}$, Cho Yon Kim³ ${ }^{3}$ Eric Martin ${ }^{4}$, Nang Thu Tt ${ }^{5}$, Frédéric Francis ${ }^{1}$, Coralie \\ Bouloiseau $^{5}$ and Nicol Picoron ${ }^{5}$
}

${ }^{1}$ Liège University (GXABT/ULg)

${ }^{2}$ Bureau of Aquaculture, DPRK

${ }^{3}$ EUPS Unit 5, DPRK

${ }^{4}$ Vietnam National University of Agriculture (VNUA)

${ }^{5}$ Triangle Génération Humanitaire (TGH)

*Corresponding author: Philippe LEBAILLY, Liège University (GxABT/ULg),

Belgium.

Received Date: August 06, 2020

Published Date: August 28, 2020

\section{Opinion}

Based on the latest United Nations Crop and Food Security Assessment Mission report (FAO/WFP, 2013), the food production in DPR of Korea (or DPRK) is focused on increasing the production of crops. Even so, diets for a main part of the population present deficiencies in proteins, lipids and micro-nutriments. Access to animal proteins is infrequent and inadequate, the provision of animal products being sporadic, depending on seasonal availability and provided in very low quantities. Only one quarter of children under the age of 2 year receive an adequately diverse diet, and only $23 \%$ of children between 6 and 24 months consumed fresh or dried fish, shellfish or seafood in the last 24 hours according to the National Nutrition Survey conducted in 2012 (CBS, 2013). Access to food is also impacted by the coverage of the Public Distribution System (PDS). Indeed, the majority of DPRK population relies on this PDS for the provision of its staple food. Consequently, DPRK people experience a high vulnerability as PDS functions very erratically (70\% of the population are PDS-dependent). In DPRK, school is compulsory from 6 years old. Before their integration to the school system, children who cannot stay at home during the day go to some preschool institutions (nurseries for the children between 0 and 4 years old and kindergarten for the children between 5 and 6 years old). These preschool institutions are named «Bo-Yuk-Ki-Kwan », meaning « care centres for the children ». These institutions are managed either by the neighbourhood committees (in urban areas only) or by an official public administration (at the level of hospitals, farms, industrial centres...).

In rural areas, nurseries and kindergarten depend most of the times on a cooperative farm. Although the children diet was more elaborated in towns than in countryside until the beginning of the 90s, this situation switched since then, farms delivering straight to the rural institutions, bypassing the PDS. The production units in charge of the food supplies for the child institutions (the cooperative farms) are largely unsupported and face low and irregular productions and thus are far to achieve their goal. As a consequence, essential needs of the children in institutions remain uncovered and their diet lacks diversity and quantity. In theory, according to the official requirements in the country, each child needs to eat a specific quantity of fish per day: 50 - 100 grams per day for children in the nurseries and $100-150$ grams per day for children in the kindergarten. This target has never been reached 
according to the field observations. To increase the food security of the children dependent on social institutions, a partnership project was formulated to improve food availability, accessibility and use, by focusing on the development of a sustainable innovative aquaculture in DPRK. As such, a research farm in Pukchang county (South Pyongyang province) has been selected to experiment new technologies and practices to improve the fish production. The targeted area is a mountainous county, with difficulties to access, impeding the food transportation from out of this region, and some current poor conditions for food production. Indeed, added to the usual lack of agricultural equipment observed throughout the country, the Pukchang county faces a lack of agricultural lands due to the presence of mines and a thermal Centre in the area. The county is thus more vulnerable on the food productions' shortage than other DPRK counties. The use of specific local resources like aquaculture production will then contribute to increase the global food consumption of the population of this county. Two European and Asian Universities (the University of Liège - Gembloux AgroBio Tech, or GxABT/ULg, the Faculty of Fisheries from the Vietnam National University of Agriculture or VNUA), one foundation supported by the official aquaculture body (the Korean Fund for Developing Fish Culture or KFDFC, supported by the Bureau of Aquaculture (BoA) under the Ministry of Fisheries), and one NonGovernmental Organization (Triangle Génération Humanitaire / TGH) are partnering for this project. The project fits with the global objective of the enhancement of resilience to food shocks for food insecure people with a particular attention to promote some nutrition sensitive activities and policies and to encourage sustainable and resilient small scale aquaculture practices (BoA, 2018).

The project initiated in 2018 intend to durably improve the animal protein intake's availability and the dietary quality for children at social institutions' level in South Pyongan province through a comprehensive approach between:

1. an intensified fish farming system based on local feed. The increase of the fish production will be sought mainly through appropriate technologies, simple and adapted to local constraints (Duong Van Thanh and al., 2012; Tran Thi Nang Thu and al, 2011).

2. the enhancement of distribution and production channels.

3. the technical and institutional strengthening towards the Ministry of Fisheries and fish farms' staff. The partners will intend to upgrade the technical and institutional capacities of the BoA based on previous lessons learnt for a more sustainable fish feeding system.
4. the strengthening of the network with abroad research actors.

5. the increase of the awareness of local population.

Created on 1st April 1962 (and it's not an April Fool's joke), the experimental farm of Pukchang has been designated as reference farm under this Partnership Project. It includes 124 ponds covered an area of 20 Jongbo (around 16.5 hectares) divided in cold water pond (6.8 ha) and warm water pond (9.7 ha).

The aquaculture farm site benefits from a quality water supply from a natural source with the following characteristics:

1. Spring water: $0.6 \mathrm{~m} 3 / \mathrm{s}$ (rainy season $0.8 \mathrm{~m} 3 / \mathrm{s}$, dry season $0.4 \mathrm{~m} 3 / \mathrm{s}$ )

2. Temperature of spring water is quite stable: $13^{\circ} \mathrm{C}$

3. Quality of water: PH7.2 / Oxygen: $6.88 \mathrm{mg} / \ell / \mathrm{H}_{2} \mathrm{~S}: 0.2$ $\mathrm{mg} / \ell$ / Nitrogen combination (mg/ $\ell$ ): $\mathrm{NH}_{4}: 0.14 / \mathrm{NH}_{3}-/ \mathrm{NO}_{2}$ : $0.063 / \mathrm{NO}_{3}:-$

The collaboration initiated under this project is primarily aimed at increasing the farm's performance to increase the quantities of fish distributed. In order to achieve this and also to have an optimal appropriation of the measures to be implemented by the Korean side, the methodology followed was to organize study trips to Belgium, France and Vietnam to see first-hand the innovations interesting things that could be put in place in Pukchang. It is very important in relation to the objective and as a warning to bear in mind the constraints faced by Korean managers of selected farms. In the first place, the objective assigned is twofold with the production of fingerlings and that of fattening fish intended to be consumed by social institutions. We have deliberately chosen to concentrate our interventions on the second objective, but it is obvious that there is permanent interference between the two production activities. Another dilemma is related to experimentation. These production farms are not intended to do research and are not willing to limit production targets because they conduct experiments. It is therefore appropriate to integrate these experiments in accordance with the production which is not always compatible.

\section{Acknowledgement}

None.

\section{Conflict of Interest}

No conflict of interest. 